\title{
Musical culture and the primary school: an investigation into parental attitudes to Whole Class Ensemble Teaching in the English primary school and potential impacts on children's musical progress
}

\begin{abstract}
Musical cultures in primary schools are influenced by motivators which include intrinsic and extrinsic factors. Whole Class Ensemble Teaching (WCET) as realised through provision from Music Education Hubs (MEH) in England, is an extrinsic factor which has been widely influential. This article explores the dynamics in play in parental engagement in music provision, as realised through domains of musical value and progression in the context of WCET provision. It presents research, based on data from one primary school in the English Midlands, drawing on responses from children, parents, the WCET teacher and the head teacher of the school. The research used semi-structured interviews and graphical elicitation as research methodologies, to create a conceptual map of theoretical perspectives for parental responses to WCET, and suggests that triangulating motivating influences from parents, WCET and learners remains an emergent domain.
\end{abstract}

Keywords: musical cultures, Whole Class Ensemble Teaching (WCET), Music Education Hubs (MEH), value, progression

\section{Introduction}

Musical cultures in schools consist of multiple inter-relating and inter-acting dynamics. The generation of such cultures in England subsists in diverse agentic constituents. These include musical histories of children and teachers within schools (MacDonald et al., 2002), perceptions of National Curriculum orders (DfE, 2013) by music teachers, relationships with musical organisations, such as Music Education Hubs (MEHs), and the influences which diverse parental perspectives bring to bear on this aggregate field. MEHs seek to draw together musical provision in a geographical area to create integrated music provision (Fautley and Whittaker, 2016). In this arrangement, the Department for Education (DfE) is often the primary funding partner, with accountability and performance monitoring structures managed through Arts Council England (ACE). One particularly dominant paradigm evident in the formation of musical cultures within primary schools, is whole class ensemble tuition (WCET), previously known as "Wider Opportunities" (Henley, 2011; 53). WCET was later developed as an entitlement for young people to learn to play a musical instrument, and to participate in ensembles, and its ideals were articulated as "core roles" in the National Plan for Music Education (DfE, 2011; 6). Evaluations of the implementation of these roles became 
part of performativity measurements on MEHs, as administered through Arts Council England (DfE, 2011).

Research reports have consistently drawn attention to the significance of parents in continuity rates, where musical activities are described as "being perceived of value in the wider community" (Hallam 2016; 7), but where continuity rates can be as low as 15\% (Hallam, 2016; 8). In 2016, the national average WCET continuation rate across all government regions in the UK was $28.87 \%$ (Fautley and Whittaker, 2016), although clarity of 'continuation routes' is an area of concern for some hubs (Fautley et al., 2017). Research responses from some MEHs have indicated that parental support, positive engagement by parents, and the importance of parental choice in continuation (Fautley et al., 2017), are significant factors in enabling continuation beyond the WCET experience for children, which often takes the form of one term of engagement (Hallam 2016, Fautley et al., 2017). This paper further investigates WCET formulations of music education in the primary school, discusses its place in enriching and enhancing musical culture in schools, and explores the parental dynamic as a motivating influence in musical learning. In the discussions which follow, the classification of 'parent' and 'parental' represents the parental role, as fulfilled though a dichotomy of caring arrangements. For the sake of clarity of discussion, 'parent' is intended to represent consistently all these potential domestic dynamics.

\section{Research Questions}

Motivations in music education are as complex as they are numerous. WCET is no different, as there are many stakeholders that play a part in the early stages of learning. To uncover motivating factors for parental engagement with music education and how these are influenced by the MEH which informs this study, this research centres its investigation around parental conceptualisations of value of musical culture in schools. Whether music possesses intrinsic value (music for music's sake), or has value that is created by what 
parents think music can do for their children, were among the questions this study sought to address. The research questions were therefore formulated as:

Q1: What seem to be the motivating factors that might encourage parents or children to want to continue with music education?

Q2: What values appear to be inherent within these attitudes?

Q3: What are the possible implications that these attitudes have on children's further progression in music education?

\section{Literature Review}

\section{Motivations in Music Education}

Intrinsic and extrinsic motivations have been generally discussed and delineated as freedom and autonomy within contextual conditions, understood in terms of basic psychological needs (Ryan and Deci, 2000). Hallam (2002) summarises extant research into motivational theory. These fall into three main groupings: motivation from within the individual (intrinsic); motivation driven by environmental factors (extrinsic); and an interaction between the two. In intrinsic and extrinsic motivations in music, political and economic factors impact musical opportunities. Political influences change the value society places on music education over time (Hallam, 2002), and the increasing pressures on Primary schools in England to raise attainment in English and Maths, means that music is increasingly being squeezed out of schools. Intrinsic motivation is therefore largely influenced by characteristics of the individual, including perceptions of musical identities, self-perception and self-awareness (Hallam, 2002; Sloboda, 1991). Sichivitsa (2007) proposes extrinsic motivation as evident in younger age groups, at earlier stages of learning, with intrinsic factors, such as self-concept emerging only in later musical engagements. Other studies with congruent findings include those in which the persistent musician benefited from external sources of motivation in the initial stages of learning (Davidson, et al., 1995). Sosniak (1985) found that parental 
encouragement through support was more important than parents' musical skills, and a commitment to assist a child as more motivational than any 'high-level' musical knowledge which a parent may possess. This raises key questions for WCET's engagement with parental support in the early stages of children's development, suggesting that triangulation of motivating influences from the parents, WCET, and learners remains a domain to be explicitly mapped.

Parental judgements on the relative worth, or values of educational activities, is already known to be significant to levels of participation (Ashbourne and Andres, 1985). However, links between parental perspectives on their children's involvement with WCET as a conduit for musical learning, and realised cultural practices within schools, remains an emerging field. Whilst studies of longitudinal development over time exist in varied contexts (Andres and Wyn, 2010), understanding the influence of cultural practices in England during developmental stages of learning, and the part parental perspectives play in this dynamic, demonstrates some divergence (Aust and Vine 2007; Scherger and Savage, 2010). A coherent narrative is therefore problematic to articulate.

\section{Value of music education}

The motivations parents identify in encouraging music in the lives of their children is evidence of how they perceive its value. Brandstrom (2000), discusses what he describes as "optional music education" $(2000 ; 36)$ centring mainly on one-to-one instrumental tuition on a variety of instruments, as social engagement, which is impacted by context, exploring the extent to which parents "use music education" $(2000 ; 36)$. He argues that whilst not directly determinate, parental background variables, including parental lifestyles and professions, influence levels of musical engagement which they facilitate for their children. Parental values therefore shape and determine contexts within which musical experiences may occur. Reeves' (2015) considers parental perceptions of musical value as nested within family traditions and notions of musicality. Development of character and attainment, in 
whatever formulation, are regarded as subsidiary to what he as describes as "natural talent" (2015; 493). Family histories in parental perspectives of musical value, therefore focus on instrumental proficiency as realised through models of one-to-one tuition. There is limited evidence that musical value is described in terms of cross-disciplinary traits or social mobility within families. In more wide-ranging discussions, Fautley (2017) discusses divergence in rationales for the inclusion of music in educational programmes, but describes the "key reasons" $(2017 ; 1)$ for music education, (within which value may subsist), as that which evidences the sentient nature of humanity, where music itself is a "powerful force" $(2017 ; 1)$. For Regelski (2002), music can have no intrinsic value as this depends on human agency operating on static elements. Despite their absence in the literature, descriptions of crosscurricular benefits, and music as an enabling force for social justice, nevertheless appear as narratives to justify musical education in the arena of public discourse. This dissonance between concerted cultivation and natural growth (Lareau, 2003), therefore demonstrates the importance of research in examining bridging moments between educational and family cultures, and the extent to which these interact and influence each other.

\section{Progression in music education}

When discussed in the context of music education, progression has been defined and interpreted in various modalities. In relation to WCET, Fautley, Kinsella and Whittaker have distinguished between progress and progression and have defined progression as:

.. to go from WCET to a school band (etc.), then to an area band, then a music centre band, and so on. In other words to make progress... and then avail oneself of progression routes available via the local hub. $(2017 ; 3)$

Music education professionals do not consistently articulate descriptions of progress and progression in this distinct manner, however, and the research from which this statement is drawn included interviews with $24 \mathrm{MEH}$ leaders who contributed more organic definitions. 
This is a problem because definitions may only be understood when used consistently by all stakeholders, including schools and parents.

In formal educational settings progression has been defined by the percentage uptake of music at Key Stage 4 (14 - 16 year olds in secondary schools) (Hallam et al., 2017). Alternative conceptualisations of progression routes that are not recognised within either a school setting, or the WCET progression route, also exist. Work initiated by the charities Awards for Young Musicians, The Musicians Benevolent Fund and Youth Music (MPR, 2012), describe individual progression journeys as more significant than only well-trodden paths, (such as graded exams), describing complex ingredients that create environments for progression. The Returning our ambition for musical learning report (MC, 2019), considers progression as formulated on axes of acquisition, application and self-actualisation, resulting in a complex and highly individualised map, unique to each learner. This model depends on the validity of its axes for its reliability and formulating progression as acquisition of knowledge is problematic for music, where knowledge can be understood in multiple dimensions. A sample of some of the discussions around musical dimensions of knowledge reveals: knowledge as active process (Paynter, 1992), knowledge as personal encounter (Swanwick, 1994), conceptual knowledge in which different discourses are enabled to speak to each other (McPhail, 2012) or as knowledge for musical meaning (Philpott, 2017). Further multiple formulations also exist, which are beyond the scope of this paper to explore. Therefore, although some discussions of musical progress exist in policy documentation and there have been some studies considering musical instrumental learning and motivation for the individual (Taylor, 2018), consideration of the dynamics of progress as conceptualised for WCET remains an area for discussion and development, hence the need for this paper.

\section{Participants and ethical considerations}


In seeking to understand the culture of WCET and to explore research questions considering musical value, progression and continuing in music education, this research gathered data from one primary school. The school was selected as a representative primary school that already participated in WCET projects provided by a music service in the English Midlands, and was engaged with music education and therefore receptive to the concept of further research into this formulation of music education. The school is a larger than average primary school with two thirds of the children from white British backgrounds, with the remaining third coming from mixed ethnic minority groups. The number of pupils who are eligible for free school meals is above average and there is also an above average percentage of children with Special Educational Needs. There are a disproportionate number of learners who start and leave the school other than at commencement and conclusion of the academic year. The school is situated on the outskirts of a city centre housing estate, the majority of which consists of social housing. All children are first generation musicians, which in this study is defined as children who do not come from families where there is a history of playing a musical instrument. A sample of seven children (year 4, $8-9$ year olds) and four parents constituted the participant group from the WCET class, the head teacher (HT), and WCET teacher for the music service (WT) engaged with the research via semi-structured interviews.

In order to ensure that research was conducted in an ethical manner, BERA (2011) ethical guidelines were adopted and informed consent was sought from all participants before the research began. The school head teacher approved the research in writing for all proposed participants, before individual permissions were also sought. Parent and WCET teacher interviewees' participated on a voluntary basis and participants were able to withdraw at any time. All children in the WCET class of the chosen school were asked to take part in the research activity. In asking all the children to participate a more informal approach that can be perceived as fun and not stressful was engendered, rather than selecting individuals and 
removing them from music lessons, potentially leaving remaining children to feel excluded or under-valued. By gathering data from some of the parents of these children, data triangulation was also possible. Anonymity of the school was also preserved by removing traceable data from results findings and all names in this article are pseudonyms.

\section{Methodology}

This study was structured as an empirical enquiry within localised boundaries of space and time (Bassey, 1999). It followed an interpretivist case study approach, enabling data emersion in a case study advocate positionality (Stake, 1995). Such a theoretical stance acknowledged research locus (Thomas, 2017), but enabled generalisability only within the confines of the study itself (Denscombe, 2010). The case study was structured as a singularity, incorporating viewpoints of multiple stakeholders to create a holistic view of a unique case (Yin, 2009).

The research project used semi-structured interviews (Pole and Lampard 2002; Kvale, 1996) for adult participants and graphical elicitation (Rouse, 2013; Wall et al., 2012) for child data. Interviews were transcribed and analysed using thematic coding (Robson, 2011), facilitated through a role-order matrix, enabling cross-data comparisons amongst participant data. Graphical elicitation was selected to enable child conceptualisations to emerge which the young participants may not otherwise have been able to articulate (Rouse, 2013). It assisted in reducing problems caused by power dynamics in child/researcher interactions, allowing greater integrity of data (Wall et al., 2012). Such an approach also facilitated themes of intrinsic/extrinsic motivating agents, and musical value as highlighted in the literature, to become evident, if present. Graphical elicitations were compared in a congruent comparative manner as semi-structured interviews, thereby facilitating triangulation of data (Newby, 2010). 
Assimilating theoretical frameworks, research questions and perspectives on motivations, progression and value, required research interactions to enable overt analysis and development. In order to facilitate this, a conceptual framework which sought to capture dynamics between the interplay of parental attitudes to WCET and implications this had for children's progression was therefore created. This representation framed the research activity which formed the core of the project and is given in Figure 1:

[Figure 1: Conceptual Framework of parental attitudes to WCET given in separate TIFF file]

\section{Data and discussion}

Following parental interviews, some uncertainty amongst these participants became evident, in relation to questions which considered the dynamics of musical interactions. (P1's closing comment "I hope that's alright?" is one example). Some interview questions were therefore modified within the interview schedule for clarity. The use of "values" also raised some difficulties, in which semantic understandings became obscured in the interview process. The head teacher identified this, describing the term as "a very culturally leading word". Questions relating to values were therefore re-framed into aspirational language, asking parents what they "hoped for" in relation to their children's education.

Children from a WCET class were asked to draw a picture of how they saw themselves in the future in relation to music, and to include anything linked to their WCET learning. These drawings were analysed through inductive analysis (Wall, 2014) and this formed the data set collected from the children (see figure 2: Example of graphical elicitation). The whole class were learning the same instrument, chosen for them by the head teacher of the school. (This is the case in a large percentage of WCET and first access music programmes where 
children are not consulted on instrumental choice (Hallam, 2002)). Questions were then applied to each of the drawings with a colour-coded system:

- What have they drawn?

- Is there any representation of music in the drawing?

- What is the location? Where are they in the drawing? (i.e. on stage, in a car)

- Is there an indication of their age in the drawing?

- How (if at all) have they interpreted the 'future'?

- Are there any links to now in the drawing? (i.e. How are they building on what they might have learnt in a WCET session?)

[Figure 2: Example of graphical elicitation given in separate TIFF file]

Using an interpretive approach, interview data were also analysed using constant comparative coding. These constructs were initially collated in table form. A small extract of research data quotations which indicates the emergent theme of a child-led paradigm is shown in Figure 3: 


\begin{tabular}{|c|c|c|c|c|c|c|c|}
\hline \multicolumn{8}{|l|}{ Themes: } \\
\hline & $\begin{array}{l}\text { Head } \\
\text { teacher } \\
(\mathrm{HT})\end{array}$ & $\begin{array}{c}\text { WCET } \\
\text { teacher } \\
\text { (WT) }\end{array}$ & $\begin{array}{c}\text { Parent } \\
1 \\
\text { (P1) }\end{array}$ & $\begin{array}{c}\text { Parent } 2 \\
\text { (P2) }\end{array}$ & $\begin{array}{c}\text { Parent } 3 \\
\text { (P3) }\end{array}$ & $\begin{array}{c}\text { Parent } 4 \\
\text { (P4) }\end{array}$ & $\begin{array}{c}\text { Parent } 5 \\
\text { (P5) }\end{array}$ \\
\hline $\begin{array}{l}\text { Progression } \\
\text { in Music } \\
\text { education is } \\
\text { child led } \\
\text { according to } \\
\text { parental } \\
\text { perspectives } \\
\text { in research } \\
\text { data } \\
\text { Italics indicate } \\
\text { child-led } \\
\text { emphases }\end{array}$ & $\begin{array}{l}\text { "It has to } \\
\text { be music } \\
\text { educatio } \\
\mathrm{n} \text { that is } \\
\text { right for } \\
\text { the } \\
\text { children } \\
\text { and it } \\
\text { has to be } \\
\text { one that } \\
\text { involves } \\
\text { parents." }\end{array}$ & $\begin{array}{l}\text { No data } \\
\text { on this } \\
\text { theme. }\end{array}$ & $\begin{array}{l}\text { "I think } \\
\text { James } \\
\text { will } \\
\text { take it } \\
\text { further } \\
\text { as he's } \\
\text { really } \\
\text { into it... } \\
\text { if } \\
\text { they're } \\
\text { enjoyin } \\
\text { g it, } \\
\text { why not } \\
\text { carry } \\
\text { on" }\end{array}$ & $\begin{array}{l}\text { "He [the } \\
\text { child] } \\
\text { wants to } \\
\text { do so } \\
\text { that's } \\
\text { why we } \\
\text { not going } \\
\text { to stop } \\
\text { anything" }\end{array}$ & $\begin{array}{l}\text { "Mary } \\
\text { always } \\
\text { wanted } \\
\text { a guitar" }\end{array}$ & $\begin{array}{l}\text { [Child } \\
\text { came } \\
\text { downstai } \\
\text { rs and } \\
\text { showed } \\
\text { mum } \\
\text { somethin } \\
\text { g he'd } \\
\text { taught } \\
\text { himself]: } \\
\text { "I think } \\
\text { it's } \\
\text { somethin } \\
\text { g he } \\
\text { likes to } \\
\text { do while } \\
\text { he's here } \\
\text { (at } \\
\text { school) } \\
\text { because } \\
\text { it's } \\
\text { somethin } \\
\text { g he's } \\
\text { just } \\
\text { doing" }\end{array}$ & $\begin{array}{l}\text { [When asked if } \\
\text { she would } \\
\text { have actively } \\
\text { sought out } \\
\text { music lessons } \\
\text { for her child, } \\
\text { parent said:] "If } \\
\text { it was } \\
\text { something she } \\
\text { wanted to do" } \\
\\
\text { "There's no } \\
\text { point in trying } \\
\text { to force them } \\
\text { to do it... if } \\
\text { they don't want } \\
\text { to, if they're } \\
\text { not interested" }\end{array}$ \\
\hline
\end{tabular}

Figure 3: Example of participant coding referenced against themes

Themes were then mapped in a network analysis (Thomas, 2017), applying hierarchical notions to them and identifying where one theme linked or arose as a result of another:

[See Figure 4: Network analysis of themes arising from interview data in separate TIFF file] 
This intertwining sub-branching of overarching and associated themes were related back to research questions, rather than the questions leading to final conclusions.

The value of music: enjoyment vs achievement

What emerged from parent interview data was the value parents placed on their children's enjoyment in music. When parents were asked what would encourage them to think about their child continuing with music, P1 commented, "If he is enjoying it then why not carry on?" and P4 "the fact that he enjoys it so much". Across the parent interview data recurring words such as love, happy and enjoyment were consistently part of parent descriptions of musical experience of their children. Hallam (2002) discusses the interplay between intrinsic motivation and personal characteristics in the early stages of positive emotional responses to music, and identifies associations and impacts for music-making. Because the parents in this study witnessed a positive emotional response from their children's involvement with music, parents encouraged their children to continue with musical engagement through WCET. Other studies have also demonstrated the significance of parental influence as a motivating factor in the initial stages of musical learning (Sichivitsa, 2007). The present study also indicates that parents and children can influence each other's attitudes to music. Because children were perceived to be enjoying music, parents interviewed supported their child's music making: "showing an interest....listening to them playing with others... because it shows that I'm interested and not just - get on with it!" (P1); "I always try and make sure he's got his instrument' (P4). Parents do not consider isolated actions such as iterating the need for practice and reminding children to bring instruments, as a necessary support to develop musical learning. Behaviours where parents encourage their children to engage in practice, therefore accompany musical activity (as parents listen to their children's musicmaking, for example). This is congruent with studies which identify parental encouragement in response to children's musical realisations as more important than parental musical skills 
per se; where a commitment to assist a child may be more motivational than, for example, possessing a high level of musical knowledge (Davidson, et al., 1996).

Parent data also contains consistent references to performing music, and how parental views of music education at school changed. P3 spoke about how beautiful the children sound "when they all play together" and P4 commented on how visible the progress they had made was, when seeing the young people's performances spread out over a period of time: "they seem to have really improved from when they did a morning assembly a while ago and then they did one recently". All parents interviewed also mentioned the recent competition that the children had performed in. Other WCET research also mentions the power of performances, summarising their role in engaging parents, and the impact of performance on children's progress in instrumental learning (Hallam, 2016).

In examining future musical projections of themselves, drawings the children produced illustrated progression through continued engagement with music. What is more difficult to determine is the link between activities the children drew, and their experiences as part of WCET. The progression they were depicting was not congruent with definitions outlined in the WCET report cited above (Fautley et al., 2017). Only one child in the class depicted themselves playing the same instrument that they were learning in WCET lessons, in contrast to the progression model suggested by Fautley et al. (2017). For the children in this research, progression was more self-led: they were clear about the music they wanted to play, the music to which they wanted to listen, and their future musical activities. For drawings analysed in detail, children also supplied a commentary. Andrew shared: "I've always wanted to play the piano...learning brass might make me better at the piano" and Lily said, "I've always liked singing and l've played the guitar at home all the time...playing brass now has helped because in the future l'd like to be a (music) teacher". So whilst links to progression on the same instrument were absent, all children depicted an ongoing engagement with music. This suggests that WCET engagement established music as part of 
the children's lives, as all included it in their future graphical projection. The children's varying drawings indicate the complex nature of progression in its various manifestations. These widely conceived and visualised natures of musical progression make it problematic to predict how individuals will develop (Lamont, 2011). This is also echoed in other recent research (Pitts, 2017), which suggests that raising awareness of progression pathways, and assisting young people in understanding links between formative music-making is critical to future musical engagement.

Young children begin to learn to play a musical instrument for a variety of reasons - and these may not be autonomous choices (Hallam, 2002). The children in this case study school learned to play through WCET because their school decided to prioritise it, by both funding the project and allowing the class and school teacher time to engage. However, analysis of visual data, questions whether children self-selecting their own instrument for WCET would mean they would engage with music-making for longer (Taylor, 2018). Whilst there is limited research into this domain, these drawings would suggest that children are clear about the instrument that they want to learn. After having been introduced to the concept of learning a musical instrument through WCET, children could be given more choice about their next steps and this in turn may have a positive effect on rates of progression.

Parental data also suggested emphasis on musical value as realised in life outcomes. These were articulated in phrases such as working as a team, building confidence, and notions of improving educational outcomes across disciplines. P3 stated: “'’m just hoping they will achieve something in life, not like me and their dad...the head teacher said, and our next door neighbour, that once you play music it helps you find a job in life. I didn't know if that was true at first". This parent had therefore developed a new value of music education through WCET. Although some have argued that there is little research indicating that parents encourage their child to engage in music education because of the traits it may 
enable in their child (Reeves, 2015), this study indicates that once children have engaged in music via WCET, parents placed increased value on the place of music education. All parents interviewed stated that they loved to listen to music and did so as a family. The children drew pictures involving listening to music on car radios and in their bedrooms. This would appear to indicate an overlap between school music and musical experience in family life. Music is therefore valued at these moments of school and home crossover, when musical enjoyment and musical development are combined. This was also evident in the interview with the head teacher: "I wanted to have a project that would have longevity and would give the children a sense of succeeding and achieving ... I believe passionately in the power of music to do that". The motivation for including music in school life was therefore about a change of culture: the musical culture of a school. Music was therefore perceived as a vehicle for cultural change, within which longevity and school engagement were critical constituents for children's progress. It was this potential for cultural change that musical education enables, that the head teacher wished to be included in parental engagements.

Although the WCET teacher's (WT) training as a music educator and musician was a different educational profile from the head teacher of the school in this study (HT did not continue with musical activity beyond her own primary school experience), both held corresponding views on the centrality of musical interactions, considering progression to be evident when schools make music an integral part of school life. WT spoke about research into music impinging on other aspects of education and attainment, suggesting that this should be highlighted to schools, noting "if head teachers can accept this, then they would go for it definitely". There is thus an intertwining of aspirations from WT and HT to create a school culture where music is embedded and forms a core of aspirational values, just as parental values inform and shape family priorities. How culture is understood within a school, and how musical values are identified, can become intertwined in the process of musical planning within a whole-school framework. HT and WT contributions to research interviews support the perspective that music justifies its place within a school by 
demonstrating its cultural value. Teaching content, and the nature of musical experience is therefore interpreted through ends beyond itself (Bowman, 2014). Where WCET programmes are individualised and offer musical choices to children, there is potential for greater musical impact within school contexts, as boundaries on how culture is understood are reconceived.

\section{Musical opportunity and school location}

Although children described musical impacts in their lives as including radio and YouTube consumption, without the school's participation in WCET, parents commented that they would not have selected musical activities for their children outside of their school context. In this scenario, WCET genuinely constitutes "first access", which is an additional synonym which appears in policy and research literature discussing WCET (Fautley et al., 2017). Parental interview responses included: "No I wouldn't have given it a second thought, a musical instrument" (P1) and "it's not something we'd really thought about until he started doing it" (P4). The socio-economic background of the school and its associated families, the cultural place of music within the lives of these families and the fact that music was only introduced to children via WCET in a musically pro-active school, highlights that multitudinous strands of musical engagement exist, each of these requires careful alignment to create a facilitating environment for first time experiences in music education, and, in turn, progression. Without WCET, therefore, musical engagement may remain outside the cultural experience of children in schools. The 'all' children is important here, as currently MEHs are being challenged with the activity of making music education more inclusive and accessible for disadvantaged pupils (Gibb, 2017). This may be a problematic aspiration when hubs are engaging with communities where music is not part of school culture and the schools are also not engaged with musical provision on offer through MEHs.

HT and WT when asked about what contributes to children progressing with learning musical instruments, both said that commitment from the school was vital, in particular 'buy- 
in' from the head teacher. Head teacher engagement has long been identified as a critical motivator to musical learning in the school environment. Ofsted charged hubs with the task of engaging in "challenging conversations" (Ofsted, 2013; 14) with schools, as one means to facilitate progression more effectively for all learners. There remains a continuing challenge with this dialogue, as schools do not have a budget that is specifically ring-fenced for music education spending, nor are they compelled to engage with the MEH offer. MEHs, and therefore children, are reliant on head teachers who value music in the curriculum, (perhaps either intrinsically, or through motivation by what it offers for school improvement), deciding to prioritise their budgets and staffing time to ensure that music, and specifically WCET, is offered in their school. This can result in an ad hoc approach to musical education, in which access and equality for all is not guaranteed. As WT stated in the research study: "I actually started in that class by accident...I got it by chance, by accident really". Many adults reflect on missed opportunities as a child, or recall that they had music education only by chance, although opportunity alone may not be enough to enable significant metamorphosis in musical outcomes (Lamont, 2011). Longer-term musical engagement is therefore facilitated through enriched interactions with stakeholders both from within, and outside of schools working together, and thereby enabling a wide variety of cultural experiences for children.

\section{Conclusions}

Analysis of data in this study reveals a complex set of philosophical values evident in the practices of those involved in the music education of children. As well as raising questions concerning the potential ad hoc nature of opportunities within current local and national manifestations of music education, WCET also emerged as a chosen medium for specific 'culture changing' purposes within the case study school. This may be a more widespread pattern, but it is not possible to draw this conclusion from research data and further investigation of culture change as facilitated through WCET is therefore required. Evidence of improvement in self-confidence and achievement gave the head teacher a reason to value WCET and invest in it on a long-term basis, consequently allowing musical progression to 
occur. This sense of value attached to musical enactions conforms to arguments that all forms of music are considered as valuable relative to their function in life (Regelski, 2002). However, perhaps more significantly, in the case of parents, data from this study also suggested that music would not previously have been a consideration for this demographic, and that value therefore emerged at a later stage, either by parents witnessing musical enjoyment or through activity at home, or musical performance in the lives of their children.

Motivation in the early stages of learning is therefore significantly influenced by levels of parental support, and there would appear to be a role for music hubs to discuss with parents how they can further enable such interactions for musical progression. One of the most significant findings from this research project was the importance of child agency in articulating instrumental selection, and the impact of this on musical development. This connects to 'school' music as experienced by children, where it has the potential to fulfil an institutional function (Regelski, 2002). Other recent research has also discussed the significance of musical agency in breaking down barriers and increasing school engagement for young people (Kinsella, et al., 2019). Child participant graphical elicitations revealed engagements with music in multitudinous interactions: as listeners, performers and educators, each retaining original ideas and identity characteristics. This study therefore concludes that it is relevant to consider how music could become part of home and school life in order to facilitate what is essentially 'first access' without boundaries. Raising awareness of progression-pathways with children and parents, and establishing links between formative music-making and future interactions (Pitts, 2017), could lead to more meaningful long-term engagements in musical activity in schools, and underpin musical development in the lives of young people, and in the experiences of their families.

\section{References}


Andres, L. and Wyn, J. (2010). The Making of a Generation: the children of the "70s in adulthood. Toronto: Toronto University Press.

Aust, R. A. and Vine, L. (2007). Taking Part: The National Survey of Culture, Leisure and Sport: Annual Report 2005/2006. London: Department for Culture, Media and Sport.

Ashbourne, D. and Andres, L. (2015). Athletics, Music, Languages, and Leadership: How parents influence the extracurricular activities of their children. Canadian Journal of Education, 38 (2), pp. 3-34.

Bassey, M. (1999). Case study research in educational settings. Buckingham: Open University Press.

BERA (2011). Ethical Guidelines for Educational Research. London: BERA.

Boal-Palheiros, G. M. and Hargreaves, D. J. (2001). 'Listening to music at home and at school. British Journal of Music Education, 18 (2), pp. 103-18.

Brandstrom, S. (2000). For whom is music education intended? Bulletin Of The Council For Research In Music Education. 147, pp. 36-39.

Bowman, W. (2014). The Ethical Significance of Music Making. Retrieved from: https://jfin107.wordpress.com/scholarly-paper-the-ethical-significance-of-music-makingbywayne-bowman/. Accessed on: 07/08/18.

Denscombe, M. (2010). The Good Research Guide for small scale social research projects ( $4^{\text {th }}$ edition). Berkshire: Open University Press.

Davidson, J.W., Sloboda, J.A. and Howe, M.J.A. (1996). The Role of Parents and Teachers in the Success and Failure of Instrumental Learners. Bulletin of the Council for Research in Music Education, (127), pp. 40-44.

Department for Education (2011). The Importance of Music: A National Plan for Music Education. London: Crown Copyright.

Department for Education (2013). Music Programmes of Study: Key Stage 3. London: Crown Copyright.

Fautley, M. and Whittaker, A. (2016). Key Data on Music Education Hubs 2016.

Birmingham: Birmingham City University.

Fautley, M. (2017). Music education: Why bother? British Journal of Music Education, 34 (1), pp. 1-3.

Fautley, M., Kinsella, V., and Whittaker, A. (2017). Whole Class Ensemble Teaching Research Report. Birmingham: Faculty of Health, Education and Life Sciences, Birmingham City University.

Gibb, N. (2017). Letter to Arts Council following Music Hubs Review. London: Department for Education.

Hallam, S. (2002). Musical Motivation: Towards a model synthesising the research. Music Education Research, 4 (2), pp. 225-244. 
Hallam, S. (2016). Whole Class Ensemble Teaching (WCET) Final Report. London: UCL Institute of Education and Music Mark - the UK Association for Music Education.

Hallam, S., Creech, A., and McQueen, H. (2017). Can the adoption of informal approaches to learning music in school music lessons promote musical progression?, British Journal of Music Education, 34 (2), pp. 127.

Henley, D. (2011). Music Education in England. London: Department for Culture, Media and Sport.

Kinsella, V., Fautley, M. and Whittaker, A. (2019). Exchanging Notes Research Report. Birmingham: Birmingham City University.

Kvale, S. (1996). Interviews: An Introduction to Qualitative Research Interviewing. Thousand Oaks: Sage.

Lamont, A., Hargreaves, D. J., Marshall, N. A., and Tarrant, M. (2003). Young people's music in and out of school. British Journal of Music Education, 20 (3), pp. 229-241.

Lamont, A. (2011). The beat goes on: music education, identity and lifelong learning. Music Education Research, 13 (4), pp. 369-388.

Lareau, A. (2003). Unequal Childhoods: class, race and family life. Berkeley: University of California Press.

MacDonald, A. R., Hargreaves, D.J. and Miell, D. (2002). Musical Identities. Oxford: Oxford University Press.

McPhail, G. (2012). From singular to overcrowded region: Curriculum change in senior secondary school music in New Zealand. British Journal of Music Education 29 (1), pp. 43 57.

Music Commission (2019). Retuning our ambition for music learning. London: ABRSM and ACE.

Musical Progressions Roundtable (2012). Retrieved from: http://www.musicalprogressions.org/. Accessed on 04/02/18.

Newby, P. (2010). Research Methods for Education. London: Pearson.

Ofsted (2013). Music in schools: what hubs must do. London: Crown Copyright.

Payner, J. (1992). Sound and Structure. Cambridge: Cambridge University Press.

Philpott, C. (2017). Assessment, musical meaning and the music classroom. Unpublished paper presentation at the sixth International Symposium on Assessment in Music Education: Birmingham City University, UK.

Pitts, S. (2017). What is music education for? Understanding and fostering routes into lifelong musical engagement. Music Education Research, 19 (2), pp.160-168.

Pole, C. and Lampard, R. (2002). Practical Social Investigation: Qualitative and Quantitative Methods in Social Research. Harlow: Prentice Hall.

Reeves, A. (2015). Music's a Family Thing': cultural socialisation and parental transference. Cultural Sociology, 9 (4), pp. 493-514. 
Regelski, T.A. (2002). Musical Values and the Value of Music Education. Philosophy of Music Education Review, 10 (1), pp. 49-55.

Robson, C. (2011). Real World Research (3 $3^{\text {rd }}$ edition). West Sussex: John Wiley \& Sons.

Rouse, L. (2013). A Change of View: using visual methods to explore experience in qualitative research. Retrieved from: http://blog.efpsa.org/2013/05/15/a-change-of-viewusing-visual-methods-to-explore-experience-in-qualitative-research/. Accessed on: 25/01/18.

Ryan, R. M. and Deci, E. L. (2000). Intrinsic and extrinsic motivations: classic definitions and new directions. Contemporary Educational Psychology, 25 (1), pp. $54-67$.

Scherger, S. and Savage, M. (2010). Cultural Transmission, Educational Attainment and Social Mobility. The Sociological review, 58 (3), pp. 406-428.

Sichivitsa, V.O. (2007). The influences of parents, teachers, peers and other factors on students' motivation in music. Research Studies in Music Education, 29 (1), pp. 55-68.

Sloboda, J. A. (1991). Music Structure and Emotional Response: Some Empirical Findings. Psychology of Music, 19 (2), pp. $110-120$.

Sosniak, L. A. (1985). Learning to be a concert pianist. In B.S. Bloom (ed), Developing talent in young people. New York: Ballentine.

Stake, R.E. (1995). The Art of Case Study Research. Thousand Oaks: Sage.

Swanwick, K. (1994). Musical Knowledge: intuition, analysis and music education. London: Routledge.

Taylor, N. (2018). The Best Way to Learn to Play a Musical Instrument: who, what and why. Retrieved from: http://www.psychreg.org/learn-musical-instrument/. Accessed on: 02/02/18.

Thomas, G. (2017). How to do your research project: a guide for students. (3rd edition). London: Sage.

Wall, K., Hall, E., and Woolner, P. (2012). Visual methodology: previously, now and in the future. International Journal of Research \& Method in Education, 35 (3), pp. 223-226.

Wall, K. (2014). How to do Visual Data. Retrieved from: https://www.academia.edu/7616324/How_to_do_visual_methods. Accessed on: 10/06/18.

Yin, R.K. (2009). Case study research: design and methods. (4th edition). Thousand Oaks: Sage. 

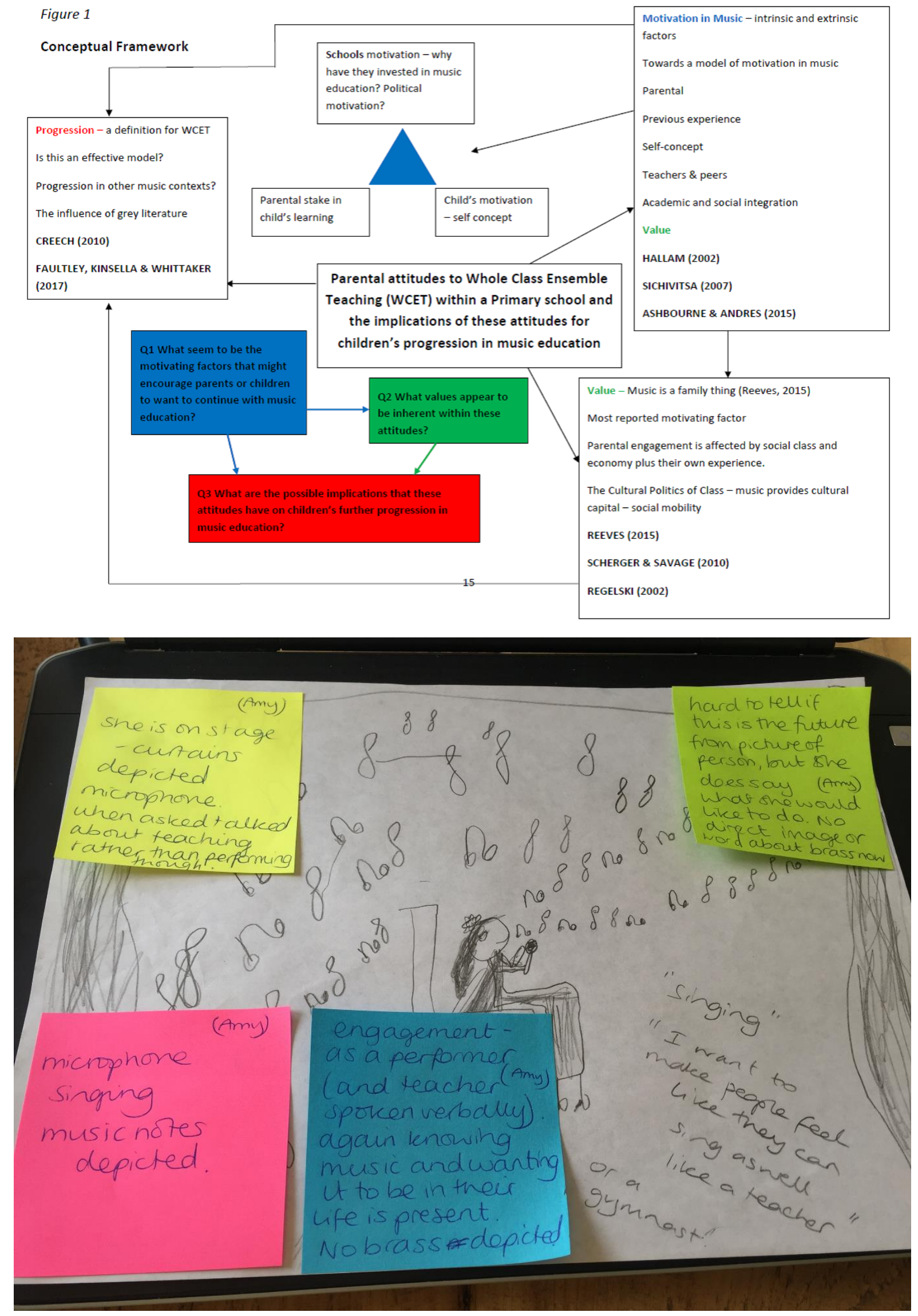


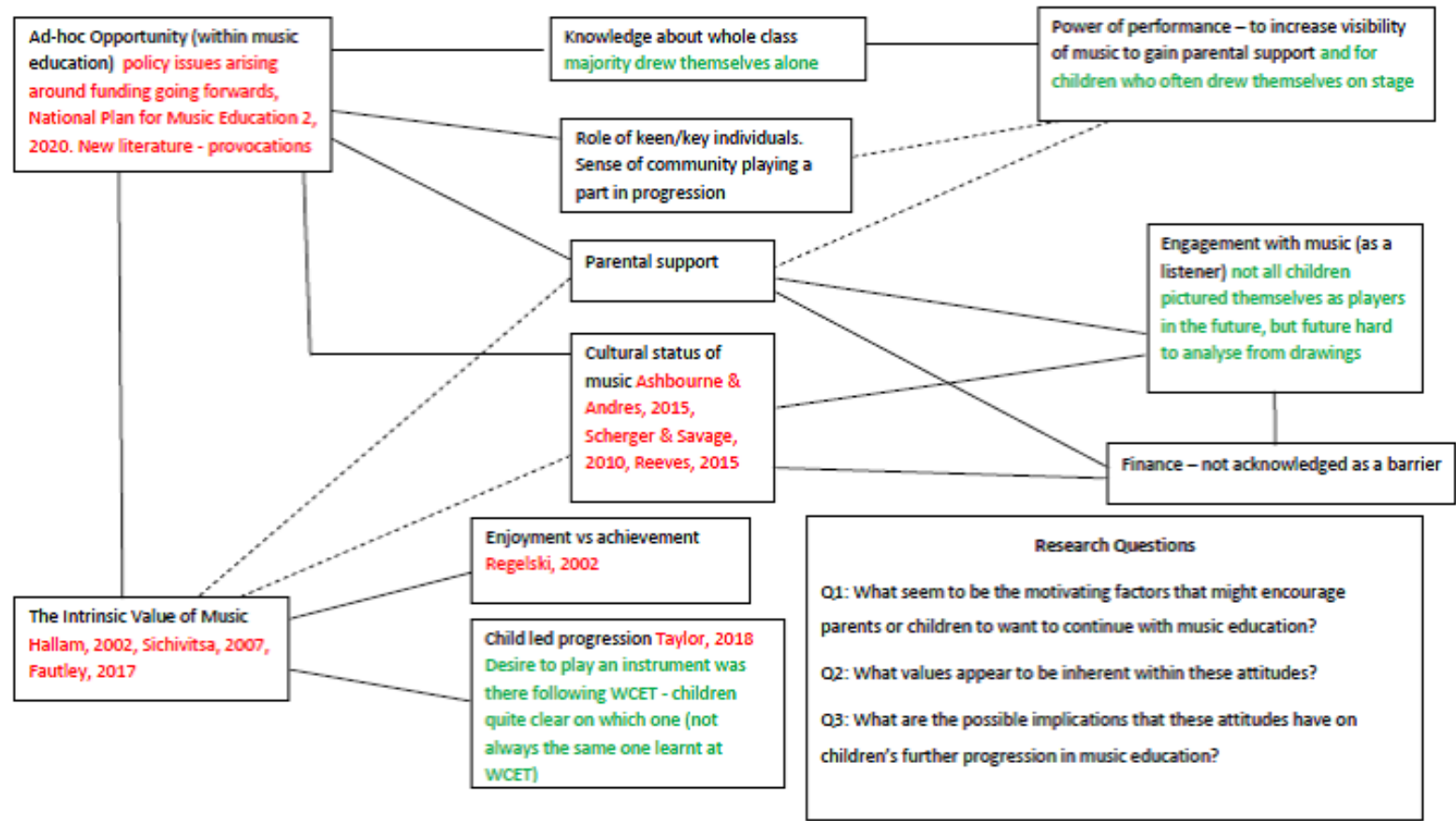

